\title{
What is
} Starting

Well?

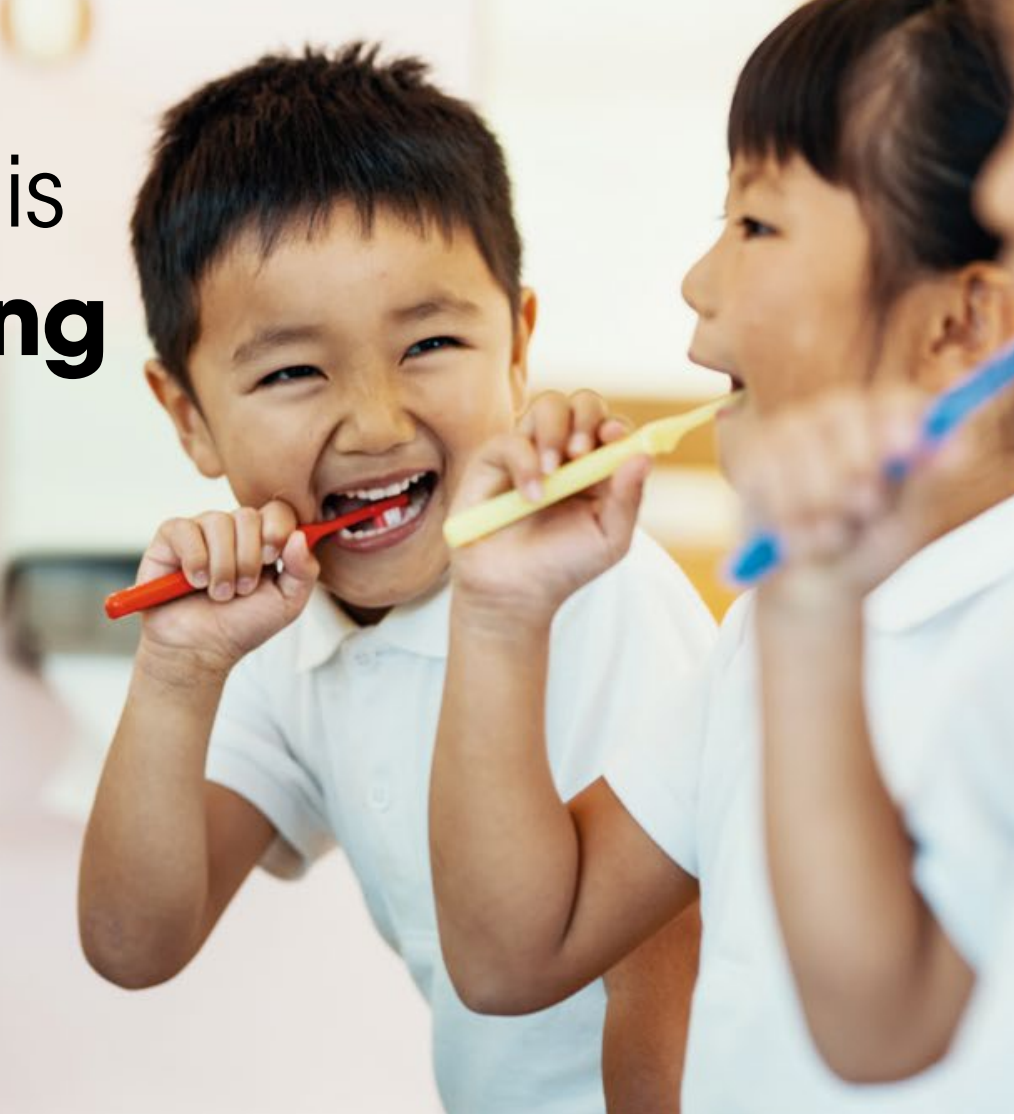

Children's oral health in some areas of the UK is devastatingly poor but, thankfully, a wealth of initiatives designed to improve prevention and reduce decay levels have sprung up in recent years. With four nations and four different systems, however, making sense of the different schemes can be a challenge. This feature by Caroline Holland will help you see the big picture and understand how Starting Well fits into it.

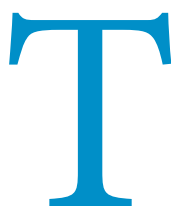

he Starting Well concept was born following a speech made by Health Minister Andrew Lansley to the British Dental Conference and Exhibition in 2011. He

promised additional funding for high priority areas, mostly where children's oral health is poorest. There are now 13 areas of the UK which have Starting Well schemes (Box 1).

Work in these areas should complement existing initiatives as well as the work of the Children's Oral Health Improvement Board. Starting Well has been a priority for Chief Dental Office (CDO) England Sara Hurley who has also overseen the development of Starting Well Core, a commissioning approach designed to reduce inequalities. It makes available a package of resources for dental practices outside of the designated 13.

The Starting Well Core initiative takes the best of existing resources, such as the British Society of Paediatric Dentistry's (BSPD's) Dental Check by One campaign, Public Health England's Change 4 Life programme and
Manchester's Baby Teeth do Matter e-learning package, and makes them available nationally. You can find out more at: https://www.england. nhs.uk/primary-care/dentistry/smile4life/ starting-well-core/.

Also a commissioning approach, it is designed to reduce oral health inequalities by:

- Increasing dental attendance for children aged 0-2

- Promoting early attendance via BSPD's Dental Check by One

- Delivering preventive care - such as fluoride varnish and healthy eating advice.

Both versions of Starting Well fall under the umbrella of England's SMILE4LIFE. Many areas have developed their own scheme. Examples include:

- Teethteam - Hull

- Brighter Smiles - Cornwall

- Keep Stoke Smiling - Staffordshire.

Meanwhile Scotland has the Childsmile scheme and Wales has Designed to Smile.
Box 1 The Starting Well 13

Blackburn with Darwen
Blackpool
Bolton
Ealing
Kingston-upon-Hull
Leicester
Luton
Middlesbrough
Oldham
Rochdale
Salford
Slough
Wakefield
https://www.england.nhs.uk/primary-
care/dentistry/smile4life/starting-
well-13/

DOI: $10.1038 / s 41407-019-0105-7$ 